\title{
Table des matières
}

1 A la recherche de performances $\quad 1$

1.1 L'organisation de projet . . . . . . . . . . . . . . 1

1.1.1 Ne jamais optimiser prématurément . . . . . . . . . . 1

1.1.2 Le processus de développement . . . . . . . . . . . . . 2

1.1.3 Bonnes pratiques de développement . . . . . . . . . . 3

1.2 Les différentes approches en $\mathrm{R}$ pour gagner en performances . . . . 9

1.2.1 Apprendre à mesurer les performances temps et mémoire . 9

1.2.2 Améliorer/optimiser le code R . . . . . . . . . . . . 15

1.2.3 Implémenter les points chauds de calcul avec des langages compilés . . . . . . . . . . . . . . . . . . 21

1.2.4 Utiliser plusieurs unités de calcul . . . . . . . . . . . . . 24

2 Fondamentaux du calcul parallèle $\quad 25$

2.1 Évolution des ordinateurs et nécessité du calcul parallèle . . . . . . 25

2.2 Les architectures parallèles . . . . . . . . . . . . . . . . . 27

2.2.1 Éléments de vocabulaire autour du processeur . . . . . . . . 28

2.2.2 Éléments de vocabulaire autour de la mémoire . . . . . . . 29

2.2.3 Typologie des infrastructures de calcul . . . . . . . . . . 35

2.3 Le calcul parallèle . . . . . . . . . . . . . . . . . . . . . . . 37

2.3.1 Éléments de vocabulaire . . . . . . . . . . . . . . 37

2.3.2 Penser parallèle . . . . . . . . . . . . . . . . . . . . . . . . . 39

2.4 Limites aux performances . . . . . . . . . . . . . . . . . 41

2.4 .1 Loi d'Amdahl . . . . . . . . . . . . . . . . . . . . . . 41

2.4 .2 Loi de Gustafson . . . . . . . . . . . . . . . . . . . 42

2.4 .3 Et dans la vraie vie . . . . . . . . . . . . . . . 43

3 Calcul parallèle avec $R$ sur machine multi-cœurs 45

3.1 Principe général . . . . . . . . . . . . . . . . 45

3.2 Le package parallel et son utilisation . . . . . . . . . . . . 46

3.2 .1 L'approche snow . . . . . . . . . . . . . . . . . . . 48

3.2 .2 L'approche multicore . . . . . . . . . . . . . . . 55

3.2 .3 foreach + doParallel . . . . . . . . . . 60 
3.2.4 Génération de nombres pseudo-aléatoires . . . . . . . . . 62

3.3 L'équilibrage de charge . . . . . . . . . . . . . . . . 63

3.3.1 Durée des tâches connue et ordonnancement statique . . . . 65

3.3.2 Durée des tâches inconnue et ordonnancement dynamique . 66

3.3.3 Granularité et équilibrage de charge . . . . . . . . . . . 70

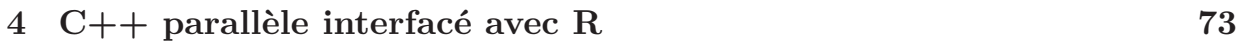

4.1 Principe général . . . . . . . . . . . . . . . . 73

4.2 openMP . . . . . . . . . . . . . . . . . . . . . 78

4.2.1 Les bases d'openMP ...................... 78

4.2 .2 R et openMP . . . . . . . . . . . . . . . . . . . . 82

4.3 Les threads de C++11 . . . . . . . . . . . . . . . . . . . 84

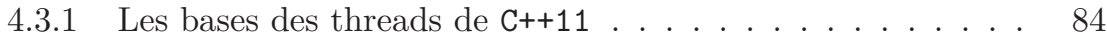

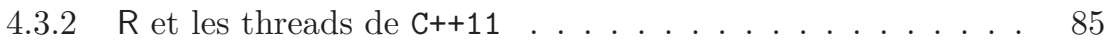

4.4 RcppParallel . . . . . . . . . . . . . . . . 87

5 Calculs et données distribués avec R sur un cluster $\quad 89$

5.1 Cluster orienté HPC . . . . . . . . . . . . . . . . . . . . 89

5.1 .1 Les bases de MPI . . . . . . . . . . . . . . 90

5.1 .2 R et MPI . . . . . . . . . . . . . . . 92

5.2 Cluster orienté big data .................... 100

A Notions complémentaires 103

A.1 Problématique du calcul flottant . . . . . . . . . . . . . . 103

A.2 La complexité . . . . . . . . . . . . . . . . . . . 104

A.3 Typologie des langages . . . . . . . . . . . . . . . 106

A.4 Les accélérateurs . . . . . . . . . . . . . . . . . . 107

A.4.1 GP-GPU, General-Purpose computation on Graphic Processing Unit . . . . . . . . . . . . . . . . 107

A.4.2 Carte many-cours ................. . . 109

A.5 Exemples d'utilisation de Rcpp avec la fonction cppfunctiondu package inline . . . . . . . . . . . . . . . . . . . . . . . 109

$\begin{array}{ll}\text { Bibliographie } & 114\end{array}$

$\begin{array}{ll}\text { Index } & 115\end{array}$ 